\title{
O conflito ambiental explicitado durante o licenciamento de um complexo portuário na "Capital Nacional do Petróleo" (Macaé - RJ)
}

\author{
The Environmental Conflict Manifested during a Port Complex Licensing in the "National Oil Capital" \\ (Macaé, Rio de Janeiro State, Brazil)
}

Resumo: 0 município de Macaé vem vivenciando, desde os anos 1970, uma drástica alteração socioespacial de seu território devido ao advento da indústria petroleira. Junto com a chegada dos empreendimentos, irromperam diversos conflitos relacionados com a indústria do petróleo. No presente trabalho, focamos em um estudo de caso: o conflito entre o Parque Nacional da Restinga de Jurubatiba e um porto que está em vias de solicitação das licenças ambientais de instalação e operação. Para entender o conflito, foram analisados alguns dos documentos publicados, como os sucessivos Relatórios de Impactos Ambientais (RIMA) elaborados pelos empreendedores, as transcrições das Audiências Públicas e alguns pareceres e ofícios emitidos pelos órgãos ambientais envolvidos. Diante das análises, observou-se que o conflito se desenrola em torno dos Estudos de Impactos Ambientais (EIA) e Relatórios de Impactos Ambientais (RIMA) apresentados pelo empreendimento, que, para pesquisadores, membros de movimentos ambientais e técnicos do ICMBio subestimaram impactos importantes sobre a Unidade de Conservação.

Palavras-chave: Conflito Ambiental. Parque Nacional da Restinga de Jurubatiba. Chantagem Locacional.
Abstract: Since the 1970s, the city of Macaé, Rio de Janeiro State, Brazil, has experienced a drastic socio-spatial alteration in its territory due to the arrival of the oil and gas industry. There were several conflicts related to the oil and gas industry with the arrival of enterprises. In the present work, we focus on a case study: the conflict between the Parque Nacional da Restinga de Jurubatiba and a seaport which is in the process of requesting environmental licenses. In order to understand the conflict, some of the published documents were analysed, such as the successive Environmental Impact Reports (RIMA, abbreviation in Portuguese) prepared by the entrepreneurs, transcripts of the public hearings, and some opinions and letters issued by the environmental agencies involved. From the analyses, it was observed that the conflict occurs around the Environmental Impact Studies (EIA, abbreviation in Portuguese) and Environmental Impact Reports (RIMA), because researchers, members of environmental movements and ICMBio experts report that important impacts on the Conservation Unit were underestimated.

Keywords: Environmental Conflict. Parque Nacional da Restinga de Jurubatiba. Local Bribery.

\section{Renata de Souza}

Formação acadêmica: Graduada em Ciências Biológicas pela Universidade Federal Fluminense (UFF). Mestre em Psicossociologia de Comunidades e Ecologia Social pela Universidade Federal do Rio de Janeiro - UFRJ. Doutoranda no curso de Pós-Graduação em Ciências Ambientais e Conservação (PPGCIAC/NUPEM/UFRJ).E-mail: resouza_1985@yahoo.com.br

\section{Rodrigo Lemes Martins}

Formação acadêmica: Graduado em Ciências Biológicas pela Universidade Federal de Uberlândia (UFU). Mestre em Biologia (Ecologia) pelo Instituto Nacional de Pesquisas da Amazônia (INPA). Doutor em Ecologia pela Universidade Federal do Rio de Janeiro (UFRJ).

E-mail: rodr.lemes@gmail.com

\section{Giuliana Franco Leal}

Formação acadêmica: Graduada em Ciências Sociais pela Universidade Estadual de Campinas (Unicamp). Mestre e Doutora em Sociologia pela Universidade Estadual de Campinas (Unicamp). Pós-doutora em Ciências Sociais na Educação pela Universidade Estadual de Campinas (Unicamp). E-mail: giulianafrancoleal@yahoo.com.br 


\section{Introdução}

Macaé é um município da Região Norte Fluminense que desponta historicamente por ser um importante entreposto para a saída de produtos da região, principalmente da agroindústria açucareira de Carapebus e Quissamã em paralelo ao escoamento de madeira da região serrana (SOFFIATI, 2011).

É interessante observar que o escoamento de produtos de origem primária ainda é um dos pilares econômicos do município através da atividade de suporte da indústria do petróleo, iniciada na década de 1970 (CRUZ, 2006; NETO, 2006). Macaé foi escolhida para sediar a unidade da Petrobras e, em decorrência disso, uma série unidades de outras empresas relacionadas direta e indiretamente com a exploração de petróleo e gás desenvolveram-se no município (SERRA; TERRA, 2006).

Conhecida como a "capital nacional do petróleo", o município apresentou, desde então, toda sua estrutura territorial e socioeconômica alterada, ocorrendo um grande fluxo migratório para Macaé devido à expectativa de criação de empregos (SOFFIATI, 2011; PIQUET, TAVARES; PESSÔA, 2017). Com a explosão populacional, o mercado de trabalho não conseguiu absorver o grande número de trabalhadores, 0 que gerou um elevado contingente de pessoas em situação de desemprego ou subemprego (SOFFIATI, 2011).

A atividade petrolífera entrou em crise a partir do final de 2014, e seus efeitos atingiram drasticamente toda a Região Norte Fluminense, especialmente Macaé. A queda na cotação do petróleo provocou a diminuição do valor dos royalties e participações especiais repassados para os municípios que, diante dessa conjuntura, diminuíram os investimentos com gastos públicos, assim como reduziram o quadro de recursos humanos das repartições públicas e suas autarquias. As demissões foram sentidas em diversos setores, embora a própria atividade de extração de petróleo tenha sido a que menos teve corte de pessoal (PIQUET, TAVARES; PESSÔA, 2017).

Nesse contexto, Piquet, Tavares \& Pessôa (2017) ressaltam a imprudência dos municípios do Norte Fluminense em não buscarem alternativas para a diversificação das atividades econômicas, visto que o setor petrolífero é bastante instável, dependente de flutuações das cotações e da geopolítica internacional, além de ser um recurso não renovável, que tende a se esgotar com as explorações.

Não obstante todas as evidências relativas à necessidade de diversificação econômica, o poder público de Macaé juntamente com grandes empresas do ramo de petróleo e gás, sustentam que a superação da crise reside na criação de um complexo portuário, o Terminal Portuário de Macaé (TEPOR) (ITI CONSULTORIA AMBIENTAL, 2018).

Apesar de ainda não edificado, o empreendimento suscitou uma série de questionamentos por parte de ambientalistas, pesquisadores e pescadores por conta dos impactos relacionados à criação de áreas de exclusão de pesca impedindo a atividade pesqueira artesanal nos locais tradicionalmente utilizados pelos pescadores; à modificação acentuada da geomorfologia costeira; ao consumo de água do empreendimento contrastando com o quadro de abastecimento precário nos bairros limítrofes a ele; à ameaça de espécies na área do empreendimento

\section{ME S T R A D 0}

PESQUISA OPERACIONAL E INTELIGÊNCIA COMPUTACIONAL

\section{LINHA DE PESQUISA EM SAÚDE}
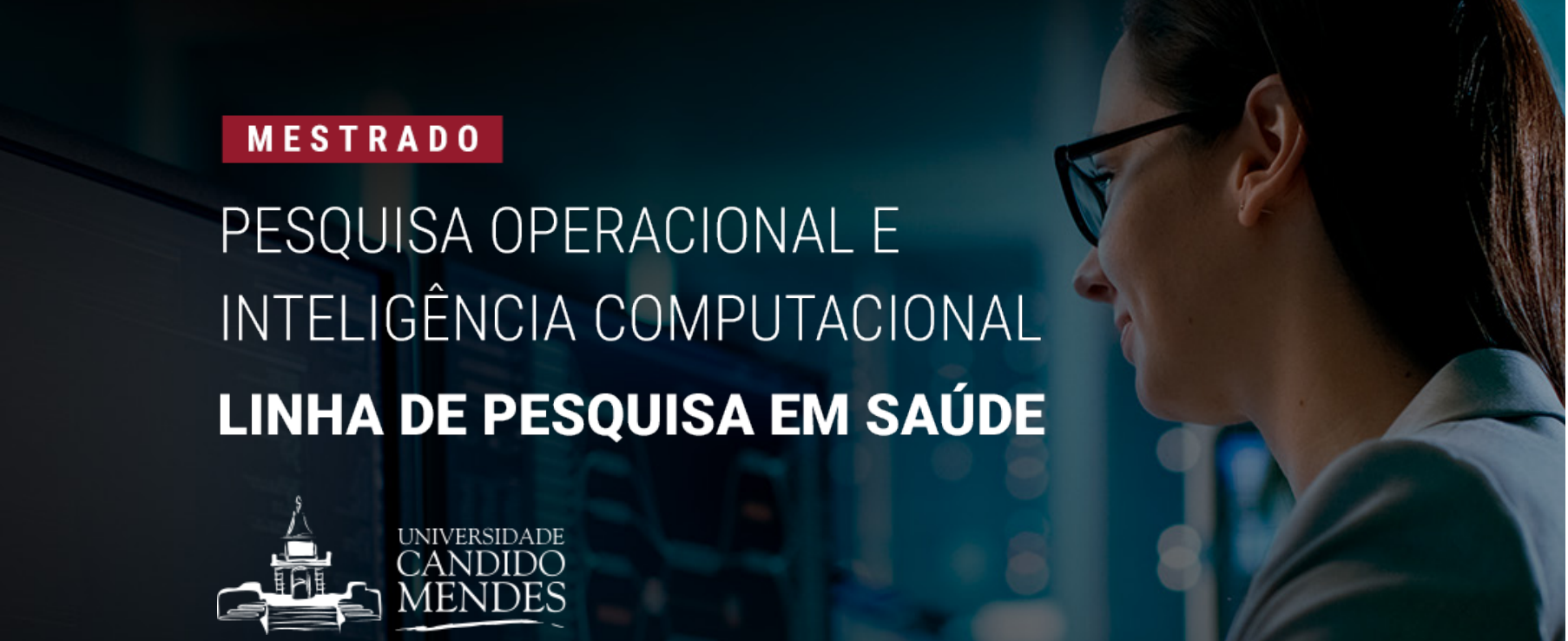
(a toninha)'; e à localização do empreendimento em Área de Preservação Permanente (CONSELHO MUNICIPAL DE MACAÉ E DESENVOLVIMENTO SUSTENTÁVEL, 2013).

Com todos os problemas acima, adiciona-se o fato do empreendimento se localizar a apenas 2,8 km do Parque Nacional (PARNA) da Restinga de Jurubatiba (PNRJ), com impactos diretos e indiretos sobre a Unidade de Conservação (UC). Entre outros problemas suscitados, pode-se listar o risco de maior insulamento do PARNA pela redução das áreas de restinga do entorno e o risco de entrada de espécies exóticas nas lagoas devido aos eventos esporádicos (naturais ou antrópicos) e pela abertura da barra das lagoas. Destaca-se também a alteração da morfologia costeira, provocando a acumulação de sedimentos na entrada da Lagoa de Jurubatiba. Tudo isso afeta diretamente os objetivos definidos para a criação do PARNA, que consiste na conservação das restingas e lagoas costeiras (INSTITUTO CHICO MENDES DE CONSERVAÇÃO DA BIODIVERSIDADE,

\section{4; INSTITUTO ESTADUAL DO AMBIENTE, 2014a).}

Vale ressaltar que o PARNA constitui-se uma Unidade de Conservação (UC); essas áreas são a forma como a natureza é protegida no Brasil desde 2000, quando foi publicada a Lei n. ${ }^{0}$ 9.985 de 18 de julho de 2000, a qual institui o Sistema Nacional de Unidades de Conservação (SNUC). 0 Parque, criado em 1998 pelo Decreto de 29 de abril de 1998, resguarda uma área de restinga e 18 lagoas costeiras situadas nos municípios de Macaé, Carapebus e Quissamã, sendo que Macaé contém a menor porção do Parque - cerca de 1\% (INSTITUTO CHICO MENDES DE CONSERVAÇÃO DA BIODIVERSIDADE, 2008) (Figura 1).

\footnotetext{
$1 \quad$ Toninhas são cetáceos presentes na Lista Oficial das Espécies da Fauna Brasileira Ameaçada de Extinção.
}

\section{Figura 1: Mapa representativo da área do Parque Nacional da Restinga de Jurubatiba, incluindo os limites municipais.}

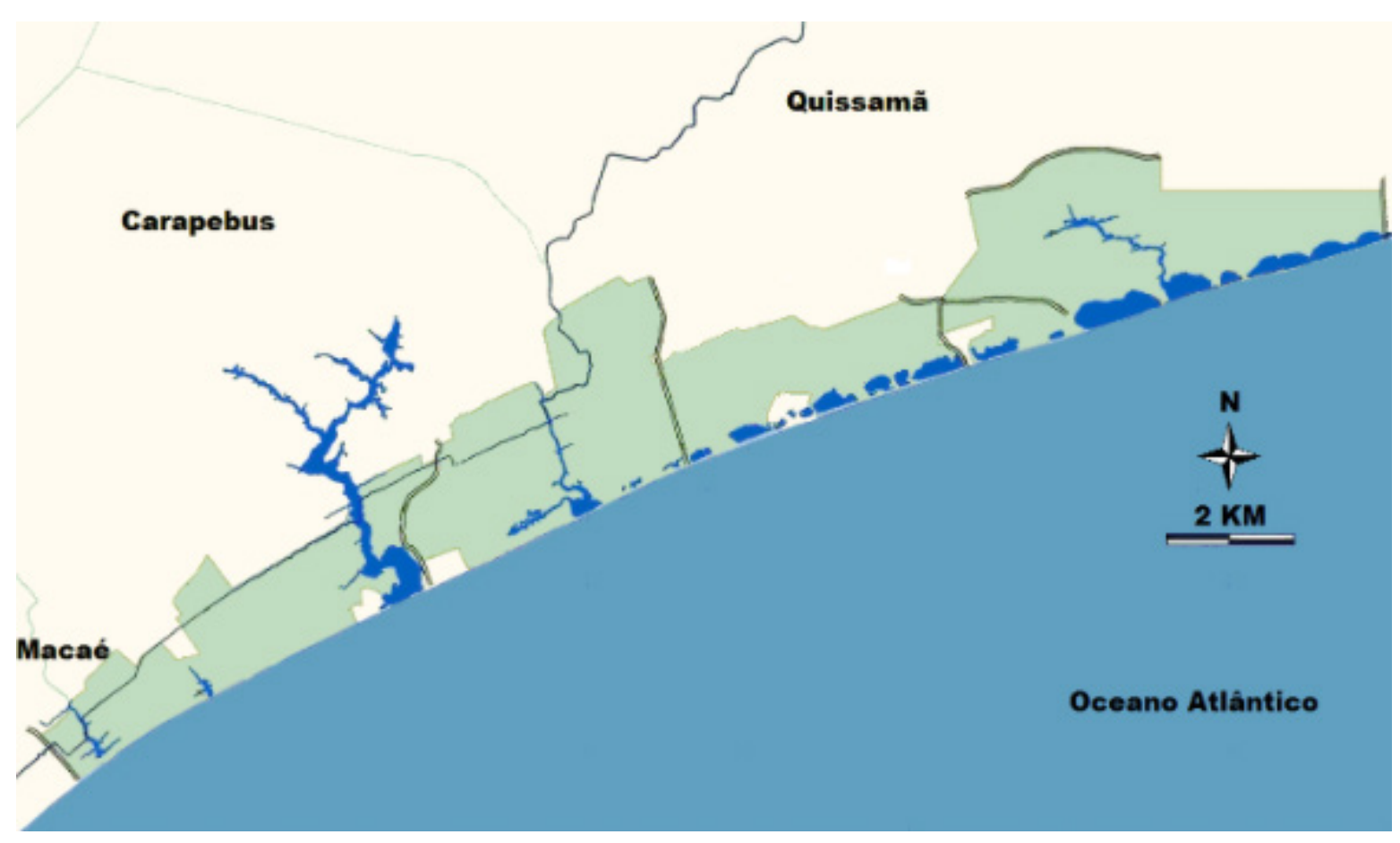

Fonte: Modificado de INSTITUTO CHICO MENDES DE CONSERVAÇÃO DA BIODIVERSIDADE (2008). 
Apesar de Macaé ser o município que resguarda a menor parte do Parque Nacional da Restinga de Jurubatiba, pode ser considerado o que exerce maior pressão sobre essa área devido, principalmente, aos impactos gerados pela cadeia produtiva do petróleo (VAINER, 2010).

Diante do quadro de conflitos de interesse com relação ao modelo de ocupação dessa faixa próxima ao Parque, o objetivo do presente trabalho consiste em analisar o conflito ambiental suscitado pela possível implementação do Terminal Portuário de Macaé (TEPOR).

Para tanto, realizou-se uma análise documental, definida por Godoy (1995) como a pesquisa em materiais que não obtiveram um tratamento prévio. Mesmo tendo tido tratamento, torna-se interessante definir um novo olhar para os dados.

Nesse sentido, foram analisados os principais documentos publicados tanto pelo Instituto Chico Mendes de Conservação da Biodiversidade (ICMBio) quanto pelo empreendimento e pelo Instituto Estadual do Ambiente (INEA), sendo estes: os três Relatórios de Impacto Ambiental (RIMA) elaborados pelo empreendimento; as ATAs e transcrições das primeira e segunda Audiências Públicas realizadas pelos empreendedores; o Parecer Técnico no 07 /2014 - ALA/ CR8/ICMBIO/RJ; o Parecer RFF n. ${ }^{\circ}$ 21/2015; a Licença Prévia concedida ao TEPOR (LP nº IN034833); e a Ação Civil Pública n. ${ }^{0}$ 5002006-45.2018.4.02.5116/RJ.

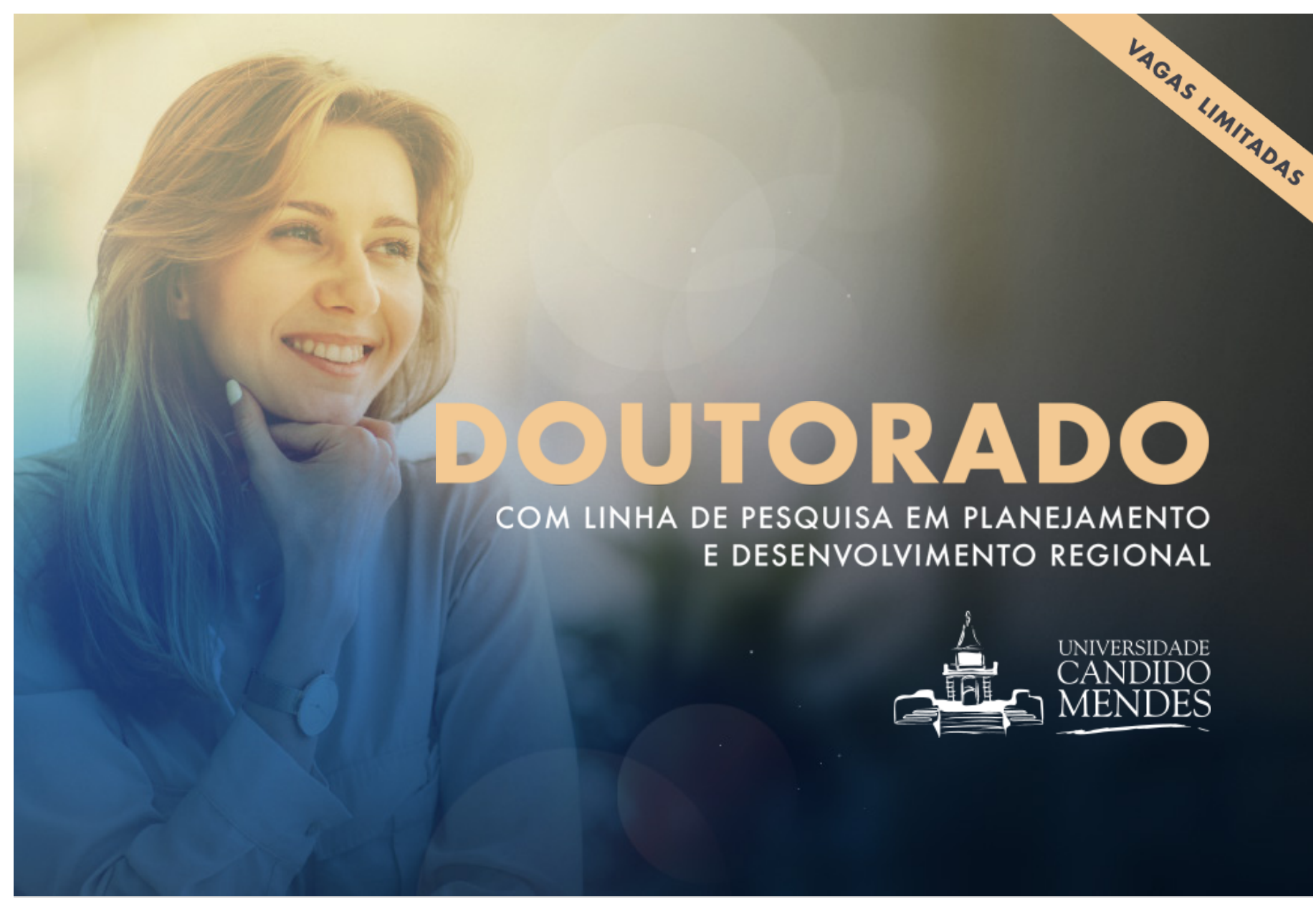




\section{Compreendendo o conflito entre 0 PARNA da Restinga de Jurubatiba e $O$ TEPOR}

O Terminal Portuário de Macaé encontra-se em vias processuais de obtenção das licenças ambientais desde 2013. O empreendimento, que está em sua segunda versão, publicou três documentos de Estudos de Impactos Ambientais (EIA) e Relatórios de Impactos Ambientais (RIMA), dois referentes a uma primeira planta de operação (publicados em 2014) e um relacionado a uma segunda versão (divulgada em 2018), assim como foram realizadas, pelos empreendedores, três Audiências Públicas, duas em 2014 e uma em 2018.

De acordo com os sucessivos RIMAs (MASTERPLAN, 2013a; MASTERPLAN, 2013b; ITI CONSULTORIA AMBIENTAL, 2018), o empreendimento visa se estabelecer na Região Norte do município de Macaé em área de vegetação de restinga. Martins, Camargo \& Leal (2017) ressaltam que essa região é distinguida da Região Sul por possuir infraestrutura urbana inadequada, alto crescimento populacional, domicílios em assentamentos precários e ser local de moradia de população de baixa renda.

É justamente nessa área que se localiza o PARNA da Restinga de Jurubatiba; em vista disso, tanto a gestão do Parque quanto pesquisadores e pesquisadoras do Instituto Federal de Educação, Ciência e Tecnologia Fluminense (IFFluminense) e da Universidade Federal do Rio de Janeiro (UFRJ) avaliam que a implantação do TEPOR contrasta com os objetivos de conservação da UC, podendo gerar impactos de grande magnitude no Parque (citados de maneira mais específica na Introdução).

Durante as Audiências Públicas realizadas nos dias 15 de janeiro e 16 de julho de 2014, os técnicos do ICMBio e diversos pesquisadores denunciaram que o EIA/RIMA do empreendimento, produzido em 2014, e sua posterior revisão subestimaram os impactos ambientais que podem incidir sobre a UC, assim como não delinearam as medidas de compensação e mitigação a serem desenvolvidas (INSTITUTO ESTADUAL DO AMBIENTE, 2014a; 2014b).

Na primeira versão do RIMA, o único impacto descrito é relativo aos ruídos produzidos na fase de instalação do porto:

As atividades portuárias irão emitir ruídos tanto na fase de instalação, com a construção das obras civis, quanto na fase de funcionamento do TEPOR, com a movimentação de navios e equipamentos e as operações decorrentes de carga e descarga. Sobreposto a isso, a área onde pretende se instalar o TEPOR é limítrofe ao bairro Lagomar e ao Parque Nacional da Restinga de Jurubatiba. Eventualmente, estes ruídos poderão trazer desconforto temporário aos funcionários de empresas vizinhas à obra e às comunidades mais próximas (MASTERPLAN, 2013a, p. 61).

\section{A QUALIDADE DE ENSINO QUE VOCE JÁ GONHECE.}

INSCREVA-SE

\section{AGORA!}

口 PRESENCIAL

口 SEMIPRESENCIAL

口 EAD

www.ucam-campos.br

22 2726-2400 
É justamente sob essa perspectiva que reside o conflito instaurado entre os analistas ambientais do ICMBio e pesquisadores e o empreendimento: na necessidade de a consultoria ambiental contratada contemplar os possíveis impactos na área do Parque e, no caso de ocorrência de impactos, a descrição das medidas de mitigação e compensação desenvolvidas, como é possível observar no Parecer Técnico n. ${ }^{0} 07$ /2014 - ALA/CR8/ICMBIO/RJ:

Este parecer concluiu pela necessidade de realização de estudos específicos sobre os impactos no Parque Nacional da Restinga de Jurubatiba e de proposição de medidas mitigadoras e compensatórias (INSTITUTO CHICO MENDES DE CONSERVAÇÃO DA BIODIVERSIDADE, 2014, p. 1).

0 parecer relata que o Instituto Estadual do Ambiente (INEA) solicitou a manifestação do ICMBio sobre o licenciamento do TEPOR, que, em resposta, declarou-se contrário à liberação da Licença Prévia sem uma revisão feita pelo EIA/RIMA que contemplasse os impactos ao Parque Nacional da Restinga de Jurubatiba. Todavia, com a veiculação da revisão 01 do EIA/RIMA (MASTERPLAN, 2013b), o que se observa é que se modificou a tipologia da área de influência do empreendimento sobre o Parque, que tramitava na primeira revisão como Área de Influência Direta do terminal portuário e na revisão 01 converteu-se em Área de Influência Indireta.

0 ICMBio, no Parecer Técnico n. ${ }^{0} 07$ /2014 - ALA/ CR8/ICMBIO/R, listou 12 possíveis impactos de grande magnitude relacionados ao PARNA, de modo direto ou indireto, e questionaram-se alguns pontos relativos ao EIA/RIMA e algumas omissões dos documentos, concluindo que:
Os estudos ambientais apresentados não identificaram quaisquer impactos ambientais incidentes no Parque Nacional de Jurubatiba, o que é inaceitável tendo em vista o porte do empreendimento e suas implicações à Unidade de Conservação explicitadas neste Parecer Técnico. Consideramos que a emissão da Autorização para o Licenciamento Ambiental deste empreendimento só será possível se estes impactos forem considerados e respectivas propostas mitigadoras ou compensatórias forem detalhadas (INSTITUTO CHICO MENDES DE CONSERVAÇÃO DA BIODIVERSIDADE, 2014, p. 38).

Em maio de 2015, o empreendedor manifestou-se a respeito do Parecer Técnico do ICMBio e alegou que já havia realizado as modificações necessárias solicitadas na revisão 01 do EIA/RIMA. Afırmou também que algumas alterações não foram realizadas, visto que estas seriam necessárias "apenas para a fase de requerimento da licença de instalação", requisitando, dessa forma, a continuidade do processo de licenciamento (INSTITUTO ESTADUAL DO AMBIENTE, 2015, p. 5).

Diante de tal afirmativa, o ICMBio emitiu o Ofício n. ${ }^{0}$ 234/2015 - CR8 Rio de Janeiro/RJ/ICMBio que solicita 0 indeferimento de todo o processo de licenciamento (INSTITUTO ESTADUAL DO AMBIENTE, 2015).

Após todos esses tramites, o INEA emitiu o Parecer RFF no 21/2015, argumentando novamente - com base na Lei n. ${ }^{0}$ 9.985/2000 e na resolução CONAMA n. ${ }^{\circ}$ 428/2010 - que o ICMBio deverá se manifestar caso 0 empreendimento afete efetivamente o PARNA ou mesmo no caso da possibilidade de afetação da UC. O ICMBio

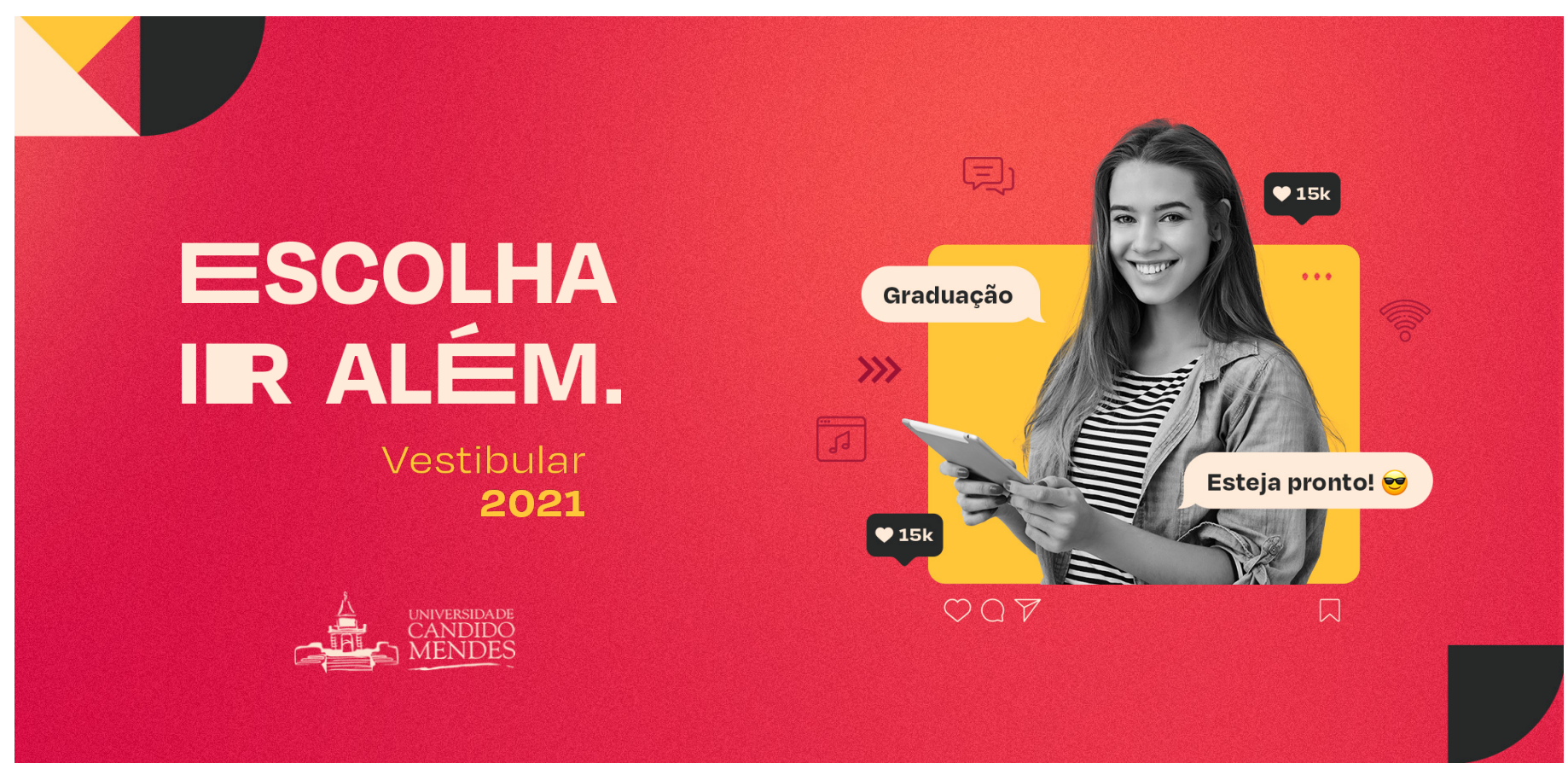


manteve seu posicionamento de críticas com relação ao EIA/RIMA, subsidiado por documentos produzidos pelo próprio ICMBio, por diversos pesquisadores de faculdades da região, pelo movimento ambientalista assim como pelo seu conselho consultivo, e conservou a solicitação de indeferimento do licenciamento.

Apesar da retórica apaziguadora estabelecida pelo INEA no Parecer RFF n.0 21/2015, esse Instituto concedeu, no dia 06 de julho de 2016, a Licença Prévia ao TEPOR (LP n. ${ }^{\circ}$ IN034833), mesmo diante da manifestação negativa do ICMBio.

Depois de toda a complexidade desse cenário, em 2016, as empresas e os acionistas envolvidos com o empreendimento foram mudados, visto que "o empreendedor, à época, teria concluído pela inviabilidade econômica do TEPOR". Devido a essa mudança, o projeto foi remodelado e instaurou-se um novo processo de licenciamento (ORGANIZAÇÃO DE DESENVOLVIMENTO CULTURAL E PRESERVAÇÃO AMBIENTAL AMA-BRASIL, 2018).

A reestruturação do processo deu origem a um novo EIA/ RIMA em setembro de 2018. 0 projeto teve seu escopo ampliado sob a justificativa de fomentar o crescimento econômico de Macaé frente à crise, tendo sido incluídas novas atividades e terminais, compreendendo a estruturação de uma unidade de regaseificação, dutovia - para o transporte de óleo e gás, através de gasodutos, oleodutos e polidutos -, unidade de processamento de gás natural e adutora para o transporte de água (ITI CONSULTORIA AMBIENTAL, 2018).

A ampliação do empreendimento, que pode gerar uma maior potencialidade nos impactos ambientais; a não observância das manifestações do ICMBio; a escassa publicização da Audiência Pública ocorrida no dia 07/11/2018; o aumento da área física do empreendimento e da movimentação de carga prevista impulsionou a Organização de Desenvolvimento Cultural e Preservação Ambiental AMA-BRASIL a ajuizar a Ação Civil Pública $n{ }^{0}$ 5002006-45.2018.4.02.5116/RJ contra o INEA, que teve como desdobramento a suspensão do licenciamento do TEPOR pela $1^{\mathrm{a}}$ Vara Federal de Macaé.

Diante desse cenário, o Movimento "Macaé Porto Já" organizou um abaixo-assinado de repúdio à Ação Civil Pública n. ${ }^{0}$ 5002006-45.2018.4.02.5116/RJ - constituído por 1868 assinaturas - e o enviou, em janeiro de 2019, ao procurador federal por meio de um ofício no qual questionava-se a decisão estabelecida pela $1^{a}$ Vara Federal de Macaé.

A sentença proferida na Ação Civil Pública n.0 5002006 45.2018.4.02.5116/RJ pela $1^{a}$ Vara Federal de Macaé é suspensa a partir de uma decisão do Tribunal Regional Federal da $2^{\text {a }}$ Região (TRF2):

Da leitura acima, não é difícil concluir pela presença dos pressupostos necessários ao deferimento da suspensão, a fim de preservar o interesse público, porquanto a manutenção dos efeitos da decisão que se busca suspender impede o prosseguimento de um empreendimento que pode gerar milhares de empregos no Município de Macaé e região, bem como pode incrementar a arrecadação do Estado do Rio de Janeiro em cerca de RS 2 bilhões de reais anuais (TRIBUNAL REGIONAL FEDERAL DA 2 a REGIÃO, 2019, p. 5).

MES T R A D 0

PESQUISA OPERACIONAL E INTELIGÊNCIA COMPUTACIONAL LINHA DE PESQUISA EM SAÚDE
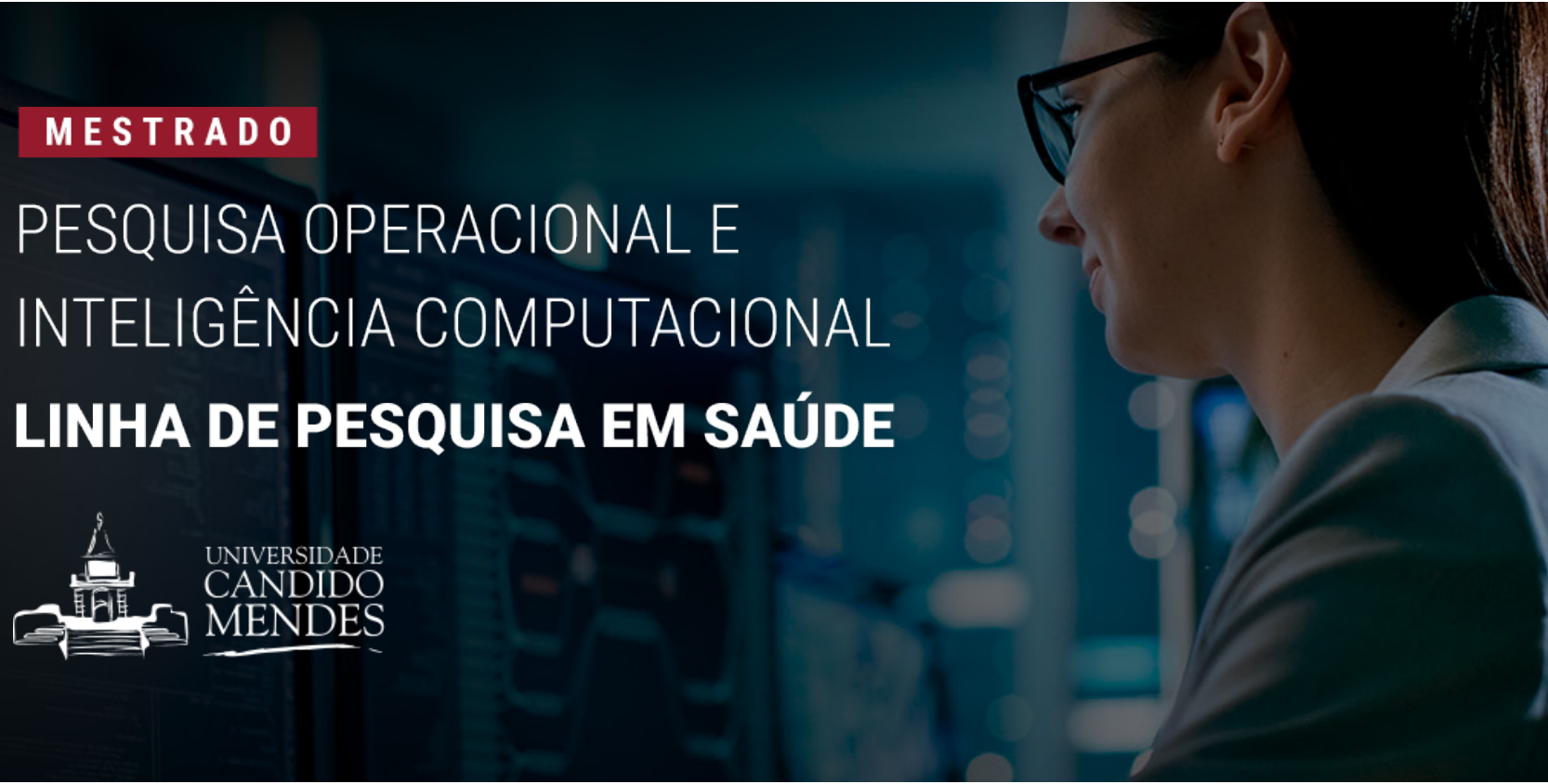
Diante desse cenário, favorável ao empreendimento, o INEA liberou, no dia 5 de novembro de 2019, a Licença Prévia (LP IN050584) ao TEPOR (INSTITUTO ESTADUAL DO AMBIENTE, 2019).

Perante tudo o que foi relatado, podemos estabelecer algumas considerações a respeito do conflito em questão. Fica evidente que a escolha da localidade a ser implantado o empreendimento é, em seu cerne, repleta de intencionalidades. 0 município de Macaé foi afetado pela crise da indústria petrolífera em 2014, gerando um contingente de desempregados, situação que deixa as pessoas mais vulneráveis diante das retóricas de crescimento econômico e geração de empregos.

Outro ponto refere-se à região do município que foi determinada para a fixação do empreendimento, a Região Norte, marcada por altos indicadores de pobreza material gerada pela divisão desigual do espaço urbano de Macaé, como demonstram Martins, Camargo \& Leal (2017). Esse quadro constitui-se na conjuntura ideal para o desenvolvimento daquilo que Acselrad (2010) denomina como chantagem locacional, definida como estratégias do grande capital de impelir para áreas carentes os riscos ambientais associados às práticas corporativistas por intermédio de uma retórica de geração de emprego e renda.

A defesa do empreendimento relacionada à empregabilidade é observada diretamente tanto nos EIA/RIMA do TEPOR quanto nas audiências públicas. Nestas últimas, ocorre tanto por parte do empreendimento como da sociedade civil e política macaense - principalmente ao analisar a transcrição da segunda audiência pública -, como é possível observar nas seguintes falas:

Primeiro, um grande potencial de geração de empregos e renda. Nós vamos ver em seguida que cada uma dessas atividades geradas de emprego dentro do terminal, nós geramos pelo menos quatro outras oportunidades de emprego indireto dentro dessa atividade, no seu suprimento logístico, na sua cadeia logística (INSTITUTO ESTADUAL DO AMBIENTE, 2014a, p. [6]).

Está um verdadeiro caos. Então vamos aproveitar que hoje a prioridade, a prioridade é o emprego, a manutenção do emprego. Então ambientalistas, briguem para tirar o máximo das empresas. Tirem compensações, mas hoje é mais importante o emprego (INSTITUTO ESTADUAL DO AMBIENTE, 2014b, p. 50).

Na página 6, destaca sobre a região do Lagomar em específico, esse capítulo é só sobre a região do Lagomar, que $41,3 \%$ da população do Lagomar não tem emprego formal. 0 que que significa isso? Significa que não tem acesso a um plano de carreira, não tem direito a férias remuneradas, não tem direito, enfim, a uma série de benefícios da CLT. Significa que quase metade da população do Lagomar tem que se virar. Nesse sentido, esses 7.400 empregos novos na Região Norte do município fazem muita diferença (INSTITUTO ESTADUAL DO AMBIENTE, 2014b, p. 51).

Outra consideração refere-se à dimensão classicista desse conflito, já que o entendimento de chantagem locacional está intrinsicamente associado ao conceito de injustiça ambiental que preconiza que a submissão aos riscos ambientais é realizada de maneira desigual, expondo as classes mais subalternas de modo mais abrupto (ACSELRAD, MELLO; BEZERRA, 2009).

Para Gramsci, a tendência dos grupos subalternos é, na disputa por hegemonia, reproduzir as ideologias dos grupos dominantes, que asseguram os interesses destes últimos (GRAMSCl, 1999). As transcrições inseridas acima demonstram justamente essa cooptação de parte da população macaense pelo capital financeiro e pelos grupos dominantes e políticos que estão por trás do TEPOR, principalmente ancorados na chantagem locacional.

Contudo, a disputa pela hegemonia não é unidirecional e, através da catarse, é possível transformar a hegemonia existente. Gramsci (1999, p. 314) define a catarse como o que acontece quando: "a estrutura (...) transforma-se em meio de liberdade, em instrumento para criar uma nova forma ético-política, em origem de novas iniciativas", sendo, desse modo, o momento catártico aquele capaz de irromper os conflitos socioambientais. Para Gramsci (1999) a catarse está estreitamente associada à atuação
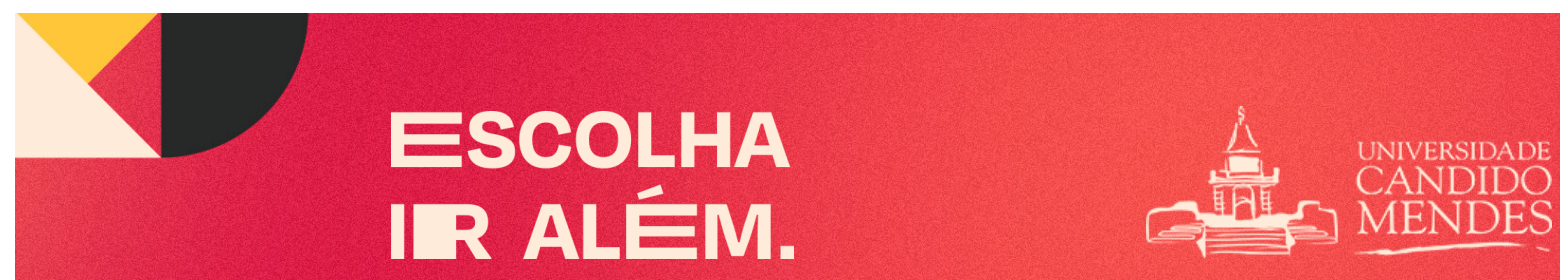
dos intelectuais orgânicos, sendo estes os responsáveis por imputar aos grupos uma reflexão crítica da realidade e por determinar as formas de organização e ação.

No nosso caso de estudo, observamos, em ambos os lados, a existência de intelectuais comprometidos com suas causas e trabalhando no sentido de indicar as formas de ação. Pesquisadores de instituições de ensino superior produziram documentos de linguagem fácil para difundir sua ideologia para a população a respeito dos impactos gerados pelo porto, que foram relevantes principalmente na primeira audiência pública, quando os investidores e a sociedade política ainda não haviam se mobilizado em grande escala para difundir suas ideologias e aliciar boa parte da população (MARTINS, CAMARG0; LEAL, 2017).

Ademais, as estratégias de confrontação direta desses pesquisadores e dos analistas ambientais do PARNA também foram observadas durante as duas primeiras audiências públicas, assim como a produção dos pareceres técnicos por parte do ICMBio e a tentativa de vetar o empreendimento no âmbito jurídico. Outra estratégia foi a criação de um movimento ambiental, o Xô Porto, que unificou os ambientalistas do município em prol dessa luta. Os membros do conselho consultivo do PARNA e os pescadores também atuaram como intelectuais orgânicos.

A disputa por hegemonia é evidente nos diversos pareceres técnicos e ofícios emitidos tanto pelo ICMBio como pelo INEA e nas notas de manifestação dos empreendedores. Nesse embate, o porto tende a alcançar a hegemonia por ter ao seu lado as classes dominantes do capital financeiro e boa parte da classe política de Macaé. A chantagem locacional confere um profundo desequilíbrio nos modos e meios de difusão de ideologia e criação de consensos assim como uma maior facilidade de acesso aos meios de comunicação de massa por parte dos investidores do TEPOR que contribuem para esse desequilíbrio.

\section{Considerações finais}

0 Parque Nacional da Restinga de Jurubatiba, de gestão do ICMBio, encontra-se, desde 2013, envolvido em um conflito de grandes proporções devido à possibilidade da instauração de um porto em suas mediações. Esse conflito é deflagrado antes mesmo da implantação do empreendimento em razão dos EIA/RIMA apresentados pelo empreendimento subestimarem impactos importantes sobre a UC.

Os embates entre os proponentes do investimento e o ICMBio/pesquisadores/alguns segmentos da sociedade civil são observados durante as audiências públicas relativas ao empreendimento e também nos diversos pareceres, ofícios e manifestações publicadas por ambos os lados. A disputa por hegemonia é, por um lado, intermediada, principalmente, pelo corpo acadêmico e pelos técnicos do ICMBio e por cidadãos e cidadãs relacionados ao movimento ambientalista de Macaé - que fazem as vias dos intelectuais orgânicos. E, por outro lado, é intercedida por alguns membros das classes políticas e pelos empreendedores.

Contudo, o que se observa com a concessão da Licença Prévia ao empreendimento e todos os embates é que a hegemonia é altamente assimétrica neste conflito devido à retórica da chantagem locacional, que alicia parte da população macaense, ao apresentar o porto como uma alternativa à crise vivenciada no município e ao sustentar a criação de empregos pelo empreendimento, mesmo sob a ameaça de degradação ambiental e os riscos sociais atrelados à alteração das condições socioambientais.

\section{Agradecimentos:}

0 presente trabalho foi realizado com 0 apoio da Coordenação de Aperfeiçoamento de Pessoal de Nível Superior - CAPES Brasil (chamada CNPQ/CAPES/ FAPs/BC-Fundo Newton - Pesquisa Ecológica de Longa Duração - PELD n. ${ }^{0}$ 15/216). 


\section{Referências}

ACSELRAD, H.; MELLO, C. C. A.; BEZERRA, G. N. O que é justiça ambiental. Rio de Janeiro: Garamond, 2009. 160 p.

ACSELRAD, H. Ambientalização das lutas sociais: o caso do movimento por justiça ambiental. Estudos Avançados, São Paulo, v. 24, n. 68 , p. 103-119, 2010.

CONSELHO MUNICIPAL DE MACAÉ E DESENVOLVIMENTO SUSTENTÁVEL (Macaé, RJ). Secretaria Municipal de Ambiente. Ata da Reunião Ordinária do dia 18 de dezembro de 2013, 18 dez. 2013. Disponível em: http://www.macae.rj.gov.br/midia/conteudo/arquivos/1396015445.pdf. Acesso em: 4 dez. 2020.

CRUZ, J. L. V. Origem, natureza e persistência das desigualdades sociais no norte fluminense. In: CARVALHO, A. M. ; TOTTI, M. E. F. (orgs.). Formação histórica e econômica do Norte Fluminense. Rio de Janeiro: Garamond, 2006. p. 33-67.

GODOY, A. S. Pesquisa qualitativa: tipos fundamentais. Revista de Administração de Empresas, São Paulo, v. 35, n. 3, p. $20-29$, 1995.

GRAMSCI, A. Cadernos do cárcere. Tradução de Carlos Nelson Coutinho. Rio de Janeiro: Civilização Brasileira, 1999. v. 1.

INSTITUTO CHICO MENDES DE CONSERVAÇÃO DA BIODIVERSIDADE. Anexo a Portaria ICMBIO n $^{\circ} 54$, de $1^{\circ}$ de agosto de 2008 , que aprova o plano de manejo do Parque Nacional da Restinga de Jurubatiba. Brasília, DF: Instituto Chico Mendes de Conservação da Biodiversidade, 1 ago. 2008. Disponível em: https://www.icmbio.gov.br/ portal/images/stories/imgs-unidades-coservacao/parna_jurubatiba.pdf. Acesso em: 4 dez. 2020.

INSTITUTO CHICO MENDES DE CONSERVACÃO DA BIODIVERSIDADE. Parecer Técnico nº 07 /2014-ALA/CR8/ICMBIO/RJ. Rio de Janeiro: Instituto Chico Mendes de Conservação da Biodiversidade, 11 dez. 2014. Disponível em: http://200.20.53.6/meioambiente/arquivos/licenciamento/parecer /249780/Parecer_T\%C3\%A9cnico_ ICMBI0\%2007_2014_GT_TEPOR_pdf. Acesso em: 8 abr. 2019.

INSTITUTO ESTADUAL DO AMBIENTE (Rio de Janeiro). Comissão Estadual de Controle Ambiental. Audiência pública do processo de licença prévia do terminal portuário de Macaé, RJ. Macaé, RJ: Instituto Estadual do Ambiente, 15 jan. 2014a. [87] p. Disponível em http://www.inea.rj.gov.br/cs/groups/public/documents/document/zwew/ mde4/ edisp/inea0018128.pdf. Acesso em: 4 dez. 2020.

INSTITUTO ESTADUAL DO AMBIENTE (Rio de Janeiro). Transcrição Audiência Pública do Licenciamento Ambiental do Empreendimento TEPOR. Macaé, RJ: Instituto Estadual do Ambiente, 16 jul. 2014b. 88 p. Disponível em: http://www.inea.rj.gov.br/cs/groups/public/documents/document/zwew/mdq3/ edisp/inea0047935.pdf. Acesso em: 4 dez. 2020.

INSTITUTO ESTADUAL DO AMBIENTE (Rio de Janeiro). Parecer RFF n² 21/2015. Rio de Janeiro: Procuradoria do Instituto Estadual do Ambiente, 19 out. 2015. Disponível em: http://200.20.53.6/meioambiente/arquivos/licenciamento/parecer/249780/RFF\%2021.15\%20-\%20E07.002.1325.2013_inv.pdf. Acesso em 6 jun. 2019.

INSTITUTO ESTADUAL DO AMBIENTE (Rio de Janeiro). Licença Prévia (LP) nº IN034833. Rio de Janeiro: Instituto Estadual do Ambiente, 6 jul. 2016. Disponível em: http://200.20.53.7/ListaLicencas/Views/pages/EspelhoLicenca.aspx?id=35063\&exibicao=0. Acesso em 3 fev. 2020.

INSTITUTO ESTADUAL DO AMBIENTE (Rio de Janeiro). Licença Prévia (LP) nº IN050584. Rio de Janeiro: Instituto Estadual do Ambiente, 5 nov. 2019. Disponível em: http://200.20.53.7/ListaLicencas/Views/pages/EspelhoLicenca. aspx?id=50911\&exibicao=0. Acesso em: 3 fev. 2020.

ITI CONSULTORIA AMBIENTAL. Projeto Terminal Portuário de Macaé (TEPOR) - Macaé/RJ: Relatório de Impacto Ambiental (RIMA). Rio de Janeiro: Iti Consultoria Ambiental, 2018. [49] p. Disponível em: http://www.inea.rj.gov.br/cs/groups/public/documents/document/bmvh/mtk5/ edisp/inea199970.pdf. Acesso em: 6 nov. 2020 .

MARTINS, R. L.; CAMARGO, G. A.; LEAL, G. F. Espaço para a extensão universitária no campo socioambiental: um estudo de caso sobre as audiências públicas do Terminal Portuário de Macaé. In: LEAL, E. M.; ESCUDERO, R. (orgs.). Problemas globais, enfrentamentos locais e a universidade pública. Macaé: Universidade Federal do Rio de Janeiro, 2017. p. 355-373.

MASTERPLAN. Relatório de Impacto Ambiental do Terminal Portuário de Macaé: revisão 00. Rio de Janeiro: Masterplan, 2013a. 75 p. Disponível em: http://www.inea. rj.gov.br/eia-rima-2013. Acesso em: 6 nov. 2020.

MASTERPLAN. Relatório de Impacto Ambiental do Terminal Portuário de Macaé: revisão 01. Rio de Janeiro: Masterplan, $2013 b$. 59 p. Disponível em http://www.inea. rj.gov.br/cs/groups/public/documents/document/zwew/mdi3/ edisp/inea0027544.pdf. Acesso em: 6 nov. 2020.

NETO, R. S. Indústria e desenvolvimento na região Norte Fluminense: crescimento econômico e o problema da extrema heterogeneidade econômico-espacial no estado do Rio de Janeiro. In: CARVALHO, A. M.; TOTTI, M. E. F. (orgs.). Formação histórica e econômica do Norte Fluminense. Rio de Janeiro: Garamond, 2006. p. 225-275.

ORGANIZAÇÃO DE DESENVOLVIMENTO CULTURAL E PRESERVAÇÃO AMBIENTAL AMA-BRASIL. Ação Civil Pública n. ${ }^{\circ}$ 5002006-45.2018.4.02.5116/RJ. Macaé, RJ: Juízo Federal da 1ª VF de Macaé, 5 dez. 2018. Disponível em: https://eproc.jfri.jus.br/eproc/externo_controlador.php?acao=processo_seleciona_publica\&num processo $=50020064520184025116 \&$ eventos=true\&num_chave $=\&$ num_chave_documento $=\&$ hash $=428 \mathrm{~d} 35 \mathrm{f} 84 \mathrm{dedca} 3 \mathrm{~b} 31056 \mathrm{fc} 16 \mathrm{cadc} 0 \mathrm{bd}$. Acesso em: $19 \mathrm{set} .2019$.

PIQUET, R.; TAVARES, E.; PESSÔA, J. M. Emprego no setor petrolífero: dinâmica econômica e trabalho no Norte Fluminense. Cadernos Metrópole, São Paulo, v. 19, n. 38, p. 201-224, 2017.

SERRA, R. V.; TERRA, D. T. Notas sobre a região petro-rentista da Bacia de Campos. In: CARVALHO, A. M.; TOTTI, M. E. F. (orgs.). Formação histórica e econômica do Norte Fluminense. Rio de Janeiro: Garamond, 2006. p. 275-307.

SOFFIATI, A. Macaé em quatro tempos. In: OFICINA SOBRE IMPACTOS SOCIAIS, AMBIENTAIS E URBANOS DAS ATIVIDADES PETROLíFERAS: 0 CASO DE MACAÉ, 2011, Niterói. Anais [...]. Niterói: UFF, 2011. p. 130-148. Disponível em: http://www.uff.br/macaeimpacto/OFICINAMACAE/pdf/21Arthur\%20Sofiatti.pdf. Acesso em: 21 mar. 2016.

TRIBUNAL REGIONAL FEDERAL DA 2a REGIÃO. Poder Judiciário. Suspensão de Liminar ou Antecipação de Tutela nº 5007181-08.2019.4.02.0000/RJ. Rio de Janeiro: Tribunal Regional Federal da $2^{\mathrm{a}}$ Região, 28 ago. 2019. Disponível em: https://eproc.trf2.jus.br/eproc/controlador.php?acao=acessar_documento_ publico\&doc=21567021493034206564112950334\&evento=21567011447358004564259229060\&key=98ac86fda2491bf7fdb12b59bd1bff8538f907771419a9ac69c822b4c32c15 91\&hash=d9cae72349bca22a51e7efab6e4b209a. Acesso em 5 dez. 2020.

VAINER, A. G. Ordenamento territorial e conflitos no Parque Nacional da Restinga de Jurubatiba. In: ENCONTRO NACIONAL DA ANPPAS, 5., 2010, Florianópolis. Anais [...]. Florianópolis: UFSC, 2010. Disponível em: http://www.anppas.org.br/encontro5/cd/artigos/GT16-421-349-20100903000806.pdf. Acesso em: 9 nov. 2020. 